\title{
PLUNCT PLACT ZUM: IMAGINAÇÃO E CRIAÇÃO ARTÍSTICA NA ESCOLA
}

\author{
Luciane Maria Schlindwein ${ }^{1}$ (D) \\ Aline Santana Martins ${ }^{l}$ iD \\ Rafael Dias de Oliveira ${ }^{2}$ (D)
}

\begin{abstract}
RESUMO: $\mathrm{O}$ artigo é parte de pesquisa que investiga a educação estética na escola, a partir dos estudos de Vigotski e das relações entre arte, imaginação e ato criador na constituição da subjetividade. Problematiza-se o papel do professor frente aos desafios do desenvolvimento estético da criança no ambiente escolar. $\mathrm{O}$ texto apresenta análises de uma intervenção artística denominada Plunct Plact Zum: vivências de criação artística realizadas com sons e sombras com criança sem um planetafantasia, desenvolvido por professores de artes, em aulas de música, em uma escola pública.
\end{abstract}

Palavras-chave: Estética. Ensino-aprendizagem. Escola. Arte. Infância.

\section{Plunct Plact Zum: artistic imagination and creation in school}

ABSTRACT: The article is part of a research that investigates Vygotsky's studies on aesthetics and the relations between art, imagination and creative act in the constitution of the subjectivity, problematizing the challenges of the person's aesthetic development in the school environment. The text

\footnotetext{
${ }^{1}$ Universidade Federal de Santa Catarina - Florianópolis (SC), Brasil.

E-mail: luciane.schlindwein@ufsc.br; alinesmar@gmail.com

${ }^{2}$ Universidade do Estado de Santa Catarina - Florianópolis (SC), Brasil.

E-mail: profrafa@gmail.com
}

DOI: 10.1590/CC0101-32622019213394 
presents analyzes of an artistic intervention called Plunct Plact Zum: experiences of artistic creation realized with sounds and shadows with children in a fantasy planet, developed by arts teachers in music classes of a public school.

KEYWORDS: Aesthetics. Teaching-learning. School. Art. Childhood.

\section{PREMISSAS INTRODUTÓRIAS}

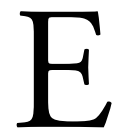

ste artigo faz parte de uma pesquisa maior que vem investigando as relaçóes que se estabelecem entre arte, imaginaçáo e ato criador na escola dos anos iniciais do ensino fundamental.

Nos últimos anos, pudemos constatar uma ampliação do olhar sobre as obras de Vigotski (1896-1934) e aproximaçóes de pesquisadores sobre seus estudos sobre a arte e a estética na vida e no desenvolvimento do homem (PINO, 2006; SCHLINDWEIN, 2006; SMOLKA, 2009; MARQUES, 2015; WEDEKIN; ZANELLA, 2016), bem como no campo da arte, em suas linguagens específicas.

Os estudos de Vigotski têm orientado nossas pesquisas sobre a formação de professores e a vivência estética, bem como sobre a relação de sujeitos com a arte, a ciência e a vida em contextos formativos, na escola (SCHLINDWEIN, 2006; SCHLINDWEIN; LATERMAN, 2016; SCHLINDWEIN; SCHULZE; MARTINS, 2016; SCHLINDWEIN; MARTINS, 2017).

Pensamos que a ideias de Vigotski sobre os processos de criação e imaginação na infância e na arte (VYGOTSKY, 2003, 2009a) têm nos permitido conceber o ensino de artes na escola como um campo de possibilidades (LATERMAN; SCHLINDWEIN, 2017) e amadurecer a ideia metodológica de "vivências estéticas" como potência para engajar o corpo do professor e da criança como um todo sensível e relacional no ambiente escolar (SCHLINDWEIN; MARTINS, 2017).

No conjunto das ideias do pensador russo há um entendimento sobre o homem e sobre o seu desenvolvimento vinculado ao contexto 
social e histórico no qual se insere, em seu meio (VYGOTSKY, 2010). Segundo o autor, o ser humano desenvolve funçóes psicológicas superiores, algo que o distingue qualitativamente de qualquer outro ser vivo e o permite simbolizar e significar a vida em relação com a natureza e o meio em que habita (PINO, 2000; VYGOTSKY, 2012).

Pino (2006) problematiza a concepção de estética na vida humana e mobiliza termos como "sensibilidade", "produção imaginária" e "atividade imaginária" para reafirmar com Vigotski a premissa basilar de que o ser humano é capaz de imaginar, sentir, criar e simbolizar. O ser humano é capaz de transformar a natureza e a si mesmo nas relaçóes com o meio, atribuindo um sentido estético em sua existência.

Nessa perspectiva, compreende-se que o desenvolvimento do homem e da criança se constitui pela vivência. Também a constituição e o desenvolvimento da docência se efetivam a partir das vivências do professor e da criança, nas relaçóes sociais e históricas que estabelecem entre si e, especialmente, no contexto escolar. Vygotsky (2010, p. 686) afirma que a vivência é "o prisma que determina o papel e a influência do meio no desenvolvimento do - digamos - caráter da criança, do seu desenvolvimento psicológico e assim por diante".

Segundo as ideias do autor, a vivência é uma unidade de análise em que o todo da personalidade se expressa — na vivência estáo materializadas as influências do meio e da disposição interior do ser humano (VYGOTSKY, 2003, 2010). Com base em suas ideias, é possível pensar que a criança e o professor habitam diferentes meios: o meio social mais amplo, o meio familiar, o meio escolar, o meio artístico e o meio da fantasia.

O recorte aqui apresentado analisa uma experiência propiciadora de relaçóes estéticas com crianças de primeiros e segundos anos do ensino fundamental, no ambiente escolar, em aulas de música. Participaram da vivência o professor de música e uma professora de teatro, em uma escola pública do município de Florianópolis, Santa Catarina. Tal experiência expressa desde a concepção, o planejamento, a realização e a análise do planeta Plunct Plact Zum.

Trata-se de um projeto de ensino de artes que propôs vivências estéticas com crianças nos anos iniciais do Ensino Fundamental, envol- 
vendo a música, o teatro de animação, a literatura e a brincadeira na escola, integrando linguagens artísticas e fundamentando-se na teoria e na metodologia da perspectiva histórico-cultural.

As turmas possuem entre 22 e 25 crianças, de acordo com a organização escolar da rede. As crianças do primeiro e do segundo ano não tiveram experiências com teatro na escola até a realização do projeto.

A ação dos professores de música e de teatro nos anos iniciais do Ensino Fundamental pode ser ressignificada em um processo de ensino-aprendizagem com arte. É possível compreender a atividade de ensino dos professores de artes como uma prática social, criativa e viva (MERCADO, 2002; VYGOTSKY, 2003).

\section{UM CONVITE METODOLÓGICO À ESCOLA: O VOO PARA O PLANETA PLUNCT PLACT ZUM}

O professor de música dos anos iniciais e a professora de teatro elaboraram um plano de trabalho pedagógico envolvendo a música, o teatro de sombras e a literatura. Plunct, Plact Zum, um planeta criado pelos professores de artes e imaginado pelas crianças, foi o lugar onde tudo aconteceu. Um planeta fantasioso, dramático, localizado na biblioteca da escola.

As situaçóes vivenciadas nesse "espaço imaginário" aconteceram no ano letivo de 2017, nos meses de novembro e dezembro, em quatro encontros de 90 minutos de duração.

Foram realizadas seis horas de atividades por turma, totalizando 24 horas de atividades. Em cada turma foi realizada uma sequência de três atividades, com as devidas adaptaçóes dos professores aos grupos de crianças na medida em que o processo foi acontecendo.

As crianças foram convidadas a habitar e imaginar esse planeta desconhecido. A biblioteca da escola foi previamente transformada para a realização das atividades. As janelas foram escurecidas e foram instalados anteparos de projeção (tela e pano branco), separando o espaço para criação de cenas atrás do anteparo e para a apreciaçáo de cenas na frente 
do anteparo, criando um espaço de plateia. Em alguns momentos, a biblioteca também foi usada para acessar livros, para confeccionar silhuetas e para criar histórias.

As atividades realizadas com as crianças foram registradas em vídeos, fotografias e em cadernos de planejamento e observação dos professores. Ao final de cada encontro, os professores dialogaram sobre as atividades realizadas no dia e replanejaram de acordo com os acontecimentos no planeta imaginário.

Esse material vem sendo analisado gradativamente com o intuito de compreender as relaçóes das crianças e dos professores com a arte no conjunto dos encontros em Plunct Plact Zum. No presente texto, analisamos o percurso do projeto e a vivência estética que denominamos como Canção da Natureza e a sombra dos animais, realizada com as crianças das turmas 11 e 22 (primeiro e segundo ano, respectivamente) na segunda semana do projeto.

Vygotsky (2009a) explica sua compreensão sobre imaginação e criação na infância. $\mathrm{O}$ autor argumenta que a relação que se estabelece entre a imaginaçáo, a fantasia e a realidade coloca em foco a atividade criadora do homem. Ao problematizar os suplícios da atividade de criaçấo do homem na relação com a arte, como música, literatura, teatro e desenho, o autor enuncia a imaginação e a arte como atividades humanas complexas, que mobilizam funçōes psicológicas como a memória, a percepção, as emoções, a imaginação e a criação.

No texto Imaginação e criação na infância: ensaio psicológico: livro para professores, publicado em russo originalmente em 1930, o autor traz algumas pistas para professores e pesquisadores pensarem em atividades que possibilitem a relação da criança com a sua imaginação e com o meio circunstancial e ambiente em que vive (VYGOTSKY, 2009a).

Ao explicar a relação da criança com o drama e com a criação na idade escolar, Vigotski expóe que o drama se constitui como um eixo de relaçáo da criança com sua realidade e com sua imaginaçáo por meio de brincadeiras de faz de conta. $\mathrm{O}$ drama torna-se a possibilidade de relacionar e analisar a vivência da criança com a criação artística. De acordo com Vygotsky (2009a, p. 98): 
Sob a forma dramática concretiza-se com maior clareza o círculo da imaginaçáo [...]. Aqui, a imagem criada com elementos da realidade encarna-se e realiza-se de novo na realidade, mesmo que de forma condicional; o impulso para a ação, para esse encarnar-se, para a realização, que está contido no próprio processo de imaginar encontra aqui sua efetivação completa.

No tal planeta das sombras, uma forma condicional compartilhada entre as crianças e os professores, a atividade de imaginar uma viagem para um planeta em que as sombras ganham vida foi iniciada por meio da canção Carimbador maluco. Na sala de aula da escola, as crianças aprenderam a cantar a canção em roda de violáo, em que os professores contaram a história de um grupo de crianças que viajavam de nave rumo a um planeta chamado Plunct Plact Zum, um planeta de sombras, inspirados na letra da canção.

Plunct Plact Zum. / Não vai a lugar nenhum! / Tem que ser selado, registrado, carimbado / Avaliado, rotulado se quiser voar! / Se quiser voar / Pra Lua: a taxa é alta / Pro Sol: identidade [...] Boa viagem, até outra vez / Plunct Plact Zum / Pode partir sem problema algum... (SEIXAS, 1983).

De acordo com o que enuncia a canção, para o voo e a habitação no planeta, as crianças teriam de passar pelo "Carimbador maluco". No faz de conta dos professores, esse personagem foi representado pelo professor de música da turma que, no caminho da biblioteca, parou o grupo e anunciou que a entrada em Plunct Plact Zum só seria possível para quem possuísse um carimbo no braço.

Além de cobrar o documento-carimbo das crianças, o professor "Carimbador maluco" contou para elas que o carimbo só seria reconhecido se todas conhecessem as regras de funcionamento do planeta, acordadas pelas crianças e pelos professores.

Anunciadas as regras pelo grupo de crianças, cada uma foi autorizada e adentrou ao planeta-fantasia. Esse procedimento foi repetido em todas as "viagens" para Plunct Plact Zum, como um rito de identificação de acesso ao espaço dramático. 


\section{O POUSO NO PLANETA: VIVÊNCIAS ESTÉTICAS DE IMAGINAÇÃO E CRIAÇÃO NA INFÂNCIA}

Foram realizadas quatro viagens até Plunct Plact Zum, uma por semana. As vivências estéticas envolveram a experimentação e a brincadeira com lanternas instaladas em pedestais para pontos de luz fixos e lanternas de mão para mobilidade (lanternas dimerizadas), materiais impressos com desenhos de objetos, com silhuetas de animais, de flores, de personagens, e materiais para confecção de silhuetas (papéis, palitos, cola, fita-crepe, gelatina de cores, folhas A4), e com instrumentos musicais (violão, xilofone, escaleta, instrumentos de percussão - reco-reco, ganzás, caxixis, tambores, baquetas, triângulo e apitos).

No processo de ensino-aprendizagem das crianças, o professor de música e a professora de teatro organizaram situaçóes de vivências em três episódios de atividades:

1. Brincando com o corpo na sombra: som e movimento (semana 1);

2. Canção da natureza e a sombra dos animais (semana 2);

3. Histórias e sons no planeta (semanas 3 e 4 ).

Os episódios envolveram brincadeiras com convenções do teatro de sombras, como manipulação de luz, projeção, criação e movimentação de silhuetas (CASATI, 2001), e pela brincadeira e pela manipulação de sons corporais, de instrumentos, em atividades de canto, sonorização de histórias, apreciação de cançóes e composição de histórias.

As atividades foram planejadas de modo a possibilitarem a experimentação e a técnica, a conhecer materiais, a manipular, apreciar, combinar e mobilizar os repertórios que possuíam de músicas, de histórias e seus conhecimentos sobre a vida. Segundo Vigotski, a experiência tem papel fundamental para a vivência da imaginação. Afirma o autor: 
A atividade da imaginação subordina-se à experiência, às necessidades e aos interesses na forma dos quais essas necessidades se expressam [...] essa atividade depende também da capacidade combinatória e do seu exercício, isto é, da encarnaçáo dos frutos da imaginação em forma material: que depende, ainda, do conhecimento técnico e das tradiçóes, ou seja, dos modelos de criação que influenciam a pessoa (VYGOTSKY, 2009a, p. 40).

As crianças das turmas 11 e 22 indicaram possuir experiência de canto e apreciaçáo de cançóes; manipular instrumentos e ouvir histórias com o professor de música. No teatro de sombras, elas indicaram inexperiência.

\section{VIVÊNCIA ESTÉTICA: CANÇÃO DA NATUREZA E A SOMBRA DOS ANIMAIS}

Amanheceu tudo é tão lindo / Ó! Meu Deus como é bom viver / A borboleta ensaia: dança, dança, dança / Dança na praia / Um beija-flor confunde o azul com azul / Aracuã, gaivota, bem-te-vi e sabiá ouvi cantar / As plantinhas orvalhadas / Andorinhas que assanhadas / A revoar / O maestro calmaria / A canção da natureza / O mar que harmonia que beleza / Canoa, eu vi o pescador voltar / Eu vi voltar do mar / Canoa, o pescador voltar do mar (GENTE DA TERRA, 2013).

Após o rito de identificação, na segunda entrada no planeta, a vivência com as crianças envolveu a apreciação e o canto da música Canção da Natureza, com apoio harmônico do violão. Nesse episódio, o professor de música participou das atividades no planeta sem estar vestido de personagem, ele atuou como professor de música e tocou para as crianças. Instrumentos de percussão e apitos foram usados pela professora de teatro para apresentar a ideia de produçáo de paisagem sonora, reproduzindo sons de animais e eventos sugeridos na canção, como o canto dos pássaros, o amanhecer, o mar, a canoa, entre outros. 
Professores e crianças cantaram a canção algumas vezes e elas foram incentivadas a também participarem na composição da paisagem sonora. Enquanto o professor de música tocava o violáo, a professora de teatro interpretava a canção com gestos e sons, alternando assovios, estalos de dedos, sons com a boca, imitação de pássaros com as mãos e posturas corporais de animais. Nesses momentos, as crianças tentavam imitar o repertório da professora e produziam seus próprios sons.

A ideia de que as sombras se movimentam com música foi uma regra sempre retomada pelos professores. No segundo encontro em Plunct Plact Zum, o professor de música reafirmou para as crianças a seguinte fala: "- As sombras se movimentam com a música que estamos colocando para tocar, mas também com a música que cada um de nós pode criar!".

Por meio dessa afirmação, o professor apresentou para as crianças um conjunto de instrumentos que poderiam ser utilizados para a produção de sons (xilofone, escaleta, instrumentos de percussão - reco-reco, ganzás, caxixis, tambores, triângulo e apitos —, além do próprio corpo — palmas, onomatopeias, estalos com dedos, com a boca).

Diante desse repertório, as crianças foram convidadas a tocar os instrumentos para movimentarem sombras com silhuetas de temas presentes na Canção da Natureza.

Nas turmas 11 e 22, as crianças foram organizadas em grupos formados por quatro integrantes. As crianças foram convidadas a criar no espaço atrás do anteparo de projeção de sombras e a fazerem uma apresentaçáo tocando e movimentando as sombras para a plateia. No processo, elas tinham à disposição silhuetas de animais presentes na canção (borboleta, gaivota, aracuâ, sabiá, bem-te-vi), instrumentos musicais e dois focos de luz (lanternas), um fixo e um móvel.

Com esse modo de proposição, os professores esperavam que as crianças se organizassem nas diferentes funçóes, que montassem uma apresentação com alguma estrutura. Porém, assim que começava a exploração nessas turmas, ficou evidente a necessidade de explorarem todos os materiais e as possibilidades antes de criarem. Todos queriam fazer um pouco de tudo: tocar os instrumentos, manipular as lanternas, manipular as silhuetas, criar sombras com o corpo. Eram muitas coisas novas de uma vez só. 
Nas análises das filmagens dessa vivência com paisagem sonora e sombra, percebemos que as crianças tentaram se organizar em duplas e trios para que tocassem juntas os instrumentos; as outras crianças manipulavam as silhuetas. A ação de produção sonora com a manipulação das silhuetas não ocorreu em todos os momentos. O que mais ficou evidente nos episódios filmados, o que mais se viu e ouviu, foram sons e movimentos aleatórios, com pouca ou nenhuma conexão entre si, ainda na fase da exploração.

$\mathrm{Na}$ segunda semana de atividades, as criaçóes das crianças ainda estavam tímidas, como açóes de quem manipula materiais e executa técnicas que ainda não domina; como quem experimenta primeiro para ver como soa, como aparece na tela, como a plateia reage, para depois poder usar isso com mais propriedade e complexidade.

Entretanto, algumas cenas gravadas mostraram momentos em que as crianças mobilizaram suas experiências na criação. É possível perceber as crianças encenando animais se beijando e brigando, por exemplo. As análises indicam, também, criaçóes coletivas em momentos nos quais duas ou mais crianças, com uma ou mais silhuetas em mãos, interagiam na tela criando situaçôes em que pássaros voavam juntos, brigavam, dançavam e assoviavam.

$\mathrm{Na}$ observação das filmagens, inferimos que as crianças por trás do anteparo de projeção de sombras, nos espaços de criação, estavam fazendo arte para elas mesmas. Estavam brincando com elementos e técnicas artísticas para se divertirem. Não aparentavam estar preocupadas em apresentar para uma plateia, mas em vivenciar aquele momento e experimentar todas as novidades possíveis propiciadas pela vivência.

Em um contexto real e ficcional entre a sala de aula e o planeta na biblioteca, foi possível pensar que as vivências de professores e crianças no meio escolar possibilitam transformaçóes na constituição de suas subjetividades, ampliando os modos de ser e estar no mundo da vida e no mundo da arte. Que por meio de relaçóes estéticas nas vivências com a arte esses sujeitos transformaram a realidade e a si mesmos, mobilizando suas memórias, suas percepçóes e suas emoçóes.

A criação da criança na brincadeira assumiu um caráter de síntese no processo de brincar. As relaçóes foram dinamizadas e en- 
fatizadas em processo. As crianças envolveram-se diretamente com os procedimentos de criação, vivenciando sua imaginação. Segundo Vygotsky (2009a, p. 17):

A brincadeira da criança não é uma simples recordaçáo do que vivenciou, mas uma reelaboraçáo criativa de impressóes vivenciadas. É uma combinação dessas impressões e, baseada nelas, a construção de uma realidade nova que responde às aspiraçôes e aos anseios da criança. Assim como na brincadeira, o ímpeto para criar é a imaginação em atividade.

A relação estética que ocorreu nas brincadeiras no jogo do faz de conta do drama, na arte, constituiu-se em possibilidades de fortalecimento da consciência criadora, apreciadora e reflexiva das crianças e dos professores nas ações no cotidiano escolar real e imaginário.

Compreendemos com base nos estudos de Vygotsky (2009b) que a imaginaçáo impulsiona o processo de criaçáo do ser humano. Como uma atividade complexa, a imaginação é ao mesmo tempo reprodução e combinação de elementos reais vivenciados por cada um de nós. Percebemos que na forma dramática a imaginação aconteceu.

Foi possível convidar as crianças para participarem de processos de educação e arte que mobilizaram vivências reais e imaginárias na atividade de criaçáo artística com sons, sombras, com a linguagem, com o conhecimento e com a vida. Ver, ouvir, cantar, atuar, manipular personagens e objetos constituíram-se em açóes concretas realizadas pelas crianças e pelos professores nesse planeta-fantasia.

\section{CONSIDERAÇÕES FINAIS}

As propostas de Vygotsky (2009b) são inspiradoras para mobilizar práticas de criação artística no ambiente escolar, tanto sob o ponto de vista da ação de ensinar como da açáo de aprender. Por meio da concepçáo e da realização do projeto Plunct Plact Zum foi possível pensar em proporcionar momentos de um processo de criação e imaginação na infância. 
Os professores realizaram um planeta fantasioso com as crianças no qual todos puderam experimentar, sentir, vivenciar e emocionar-se por meio da produção imaginária de músicas, textos, cenas e materiais artísticos.

As aulas de música e a relaçáo com o teatro proporcionaram aos professores de música e teatro planejar situações pedagógicas que ampliassem a relação estética das crianças com cada linguagem artística em particular, e com a união entre a música, a literatura e o teatro, abrindo possibilidades para o ensino de artes na escola.

Ao término do voo ao planeta, percebemos que professores e crianças se divertiram, sofreram, extravasaram, incomodaram, sentiram-se incomodados, estranharam, causaram estranhamentos, emocionaram-se e estiveram presentes no planeta, como narradores, como personagens e como crianças.

O teatro de sombras e a sua relação com a música foram significativos na escola. Histórias individuais, coletivas e pensamentos sobre relaçóes humanas foram mobilizados em um contexto ficcional e teatral, a partir de sons, gestos e palavras. Composiçóes artísticas aconteceram. Histórias foram animadas e musicadas. Um novo universo imaginário se configurou como possibilidade!

O desenvolvimento cultural da criança apresentou-se, assim, em seu caráter dialético, como um autêntico drama, configurando-se por meio de um trabalho de construção e relação do homem sobre o homem (SMOLKA, 2009, p. 10).

\section{REFERÊNCIAS}

CASATI, R. A descoberta da sombra: de Platão a Galileu: a história de um enigma que fascinou as grandes mentes da humanidade. São Paulo: Companhia das Letras, 2001.

GENTE DA TERRA. Canção da Natureza. Florianópolis: Gravadora independente, 2013.

LATERMAN, I.; SCHLINDWEIN, L.M. Que os professores perguntem, testem e brinquem. In: SCHLINDWEIN, L.M.; LATERMAN, I.; PETERS, L. (orgs.). $A$ criança e o brincar nos tempos e espaços da escola. Florianópolis: NUP/UFSC, 2017. 
MARQUES, P.N. O Vygótski incógnito: escritos sobre arte (1915-1926). 2015. 317f. Tese (Doutorado em Literatura e Cultura Russa) - Faculdade de Filosofia, Letras e Ciências Humanas, Universidade de São Paulo, 2015.

MERCADO, R.M. Los saberes docentes como construcción social: la enseñanza centrada en los nińos. México: Fondo de Cultura Económica, 2002.

PINO, A. A produção imaginária e a formação do sentido estético. Reflexóes úteis para uma educação humana. Pro-posiçôes, v. 17, n. 2, maio/ago. 2006. Disponível em: <https:/periodicos.sbu.unicamp.br/ojs/index.php/proposic/ article/view/8643628/11147 . Acesso em: $1^{\circ}$ mar. 2017.

. O social e o cultural na obra de Vigotski. Educação \& Sociedade, v. 21, n. 71, p. 45-78, 2000. http://dx.doi.org/10.1590/S0101-73302000000200003

SCHLINDWEIN, L.M. Estética e pesquisa na formação de professores. Florianópolis: Editora da Univali, 2006.

SCHLINDWEIN, L.M.; LATERMAN, I. Arte e ciência na formação dos professores dos anos iniciais. In: ROMANOWSKI, J.P; MARTINS, P.L.O.; CARTAXO, S.R.M. (orgs.). Práticas de formação de professores: da educação básica à educação superior. Curitiba: PUC Press, 2016.

SCHLINDWEIN, L.M.; MARTINS, A.S. Vivência estética e formação de professores. In: CONGRESSO NACIONAL DE EDUCAÇÃO, 13., 2017, Curitiba. Formação de professores: contextos, sentidos e práticas. 2017.

SCHLINDWEIN, L.M.; SCHULZE, M.D.; MARTINS, A.S. Estética e docência: a dimensão do sensível na formação de professores para a infância. In: SEMINÁRIO DE GRUPOS DE PESQUISA SOBRE CRIANÇAS E INFÂNCIAS, 5., 2016, Florianópolis. Anais... 2016.

SEIXAS, R. Carimbador maluco. São Paulo: EMI-Odeon, 1983.

SMOLKA, A.L. Apresentação - A atividade criadora do homem: a trama e o drama. In: VYGOTSKY, L.S. Imaginação e Criação na Infância. São Paulo: Ática, 2009.

VYGOTSKY, L.S. Génesis de las funciones psíquicas superiores. In: Problema del desarollo de psique. Madri: Machado Grupo de Distribuición, 2012. (Obras Escogidas, III).

- Imaginação e criação na infância: ensaio psicológico: livro para professores. São Paulo: Ática, 2009a. 135 p. 
. Pensamento e Palavra. In: . A construção do pensamento e da linguagem. Tradução de Paulo Bezerra. 2. ed. São Paulo: WMF Martins Fontes, 2009b.

- Psicologia Pedagógica. Tradução de Cláudia Schilling. Porto Alegre: Artmed, 2003.

Quarta aula: a questáo do meio na pedologia. Tradução de Márcia Pileggi Vinha. Psicologia USP, São Paulo, v. 21, n. 4, p. 681-701, 2010. https:// doi.org/10.1590/S0103-65642010000400003

WEDEKIN, L.M.; ZANELLA, A.V. L. S. Vigotski e o ensino de arte: "A educação estética” (1926) e as escolas de arte na Rússia 1917-1930. Pro-Posiçôes, v. 27, n. 2, p. 155-176, 2016. Disponível em: <http://www.scielo.br/scielo. php?pid=S0103-73072016000200155\&script $=$ sci abstract\&tlng=PT $>$. Acesso em: 8 mar. 2017.

Recebido em 24 de agosto de 2018.

Aprovado em 11 dezembro de 2018. 